\title{
Зрение и спортивный дайвинг
}

\author{
УДК 617.7+613.62-02-07-08:797.215+613.643
${ }^{1}$ Е. А. Крючина, ${ }^{1,2}$ И. В. Трухан, ${ }^{2}$ А. Б. Салтыков, ${ }^{3}$ С. М. Шанойло

\author{
1Городская клиническая больница № 10, Киев, Украина \\ 2 ID'C club, Киев, Украина \\ ${ }^{3}$ Институт проблем регистрации информации НАН Украины, Киев, Украина
}

Резюме. Мета. Узагальнити дані літератури щодо фізіології та патології зорового аналізатора в підводному середовищі, зокрема під час занять спортивним дайвінгом.

Методи. Теоретичний аналіз і узагальнення, систематизація, аналіз наукової та науково-методичної літератури.

Результати. Проведено аналіз літератури з використанням електронних наукометричних баз даних Scopus, Web of Science, Ulrich's Periodicals, eLIBRARY.RU, Google Scholar, PubMed, Medline, українських і російських баз даних, друкованих наукових статей, монографій і посібників, присвячених спортивному дайвінгу, підводній і гіпербаричній медицині та патології органа зору за період з 1950 по 2015 р. У роботі розглянуто питання впливу підводного середовища на функцію зорового аналізатора, особливості конструкції та використання підводної оптики, фітнес-дайвінгу (у тому числі після різних варіантів перенесених оперативних втручань на оці) при офтальмологічній патології. Представлено сучасні класифікації, особливості етіології, патогенезу, клініки, діагностики та лікування гострої і хронічної патології органа зору, пов'язаної зі спортивним дайвінгом, водолазними і кесонними роботами, описані показання до проведення гіпербаричної оксигенотерапії у пацієнтів з офтальмологічною патологією, запропоновано новітні напрями розширення можливостей опанування підводного середовища у осіб патологією органа зору.

Висновки. Загальною характерною особливістю впливу підвищеного тиску на організм є зворотний характер змін, що відбуваються у функціонуванні ряду фізіологічних систем організму. До ускладнень і специфічних захворювань призводять порушення правил і режимів спусків під воду, а також недооцінка морфофункціонального стану дайвера (водолаза, кесонного робітника) перед зануренням.

Ключові слова: спортивний дайвінг, патологія зору.

\begin{abstract}
Aim. To summarize the literature data on the physiology and pathology of the visual analyzer in the underwater environment, especially sports diving.

Methods. Theoretical analysis and generalization, classification, analysis of scientific and methodical literature.

Results. The analysis of the literature was carried out using electronic scientometric database Scopus, Web of Science, Ulrich's Periodicals, eLIBRARY.RU, Google Scholar, PubMed, Medline, Ukrainian and Russian data of bases, published scientific articles, textbooks and guidelines devoted to sport diving, underwater and hyperbaric medicine and pathology the organ of vision for the period 1950 to 2015. The paper discusses issues of influence of the underwater environment on the function of the visual analyzer, design features and the use of underwater optics, fitness diving (including after various types surgical interventions on the eye) with ophthalmic pathology. It presents modern classification, features of etiology, pathogenesis, clinical manifestations, diagnosis and treatment of acute and chronic pathology of the vision associated with sport diving, underwater and caisson work described indications for hyperbaric oxygen therapy in patients with ophthalmic pathology, offered new avenues for expansion absorptive capacity underwater environment for people with disorders of the vision.

Conclusions. A common feature of the impact of increased pressure on the body is reversible nature of the changes in the functioning of many physiological systems of the body. Complications and specific diseases cause violation of the rules and modes of descents into the water, as well as an underestimation of the morphofunctional state of the diver (divers, caisson workers) before the dive.

Keywords: sports diving, vision pathology.
\end{abstract}

Постановка проблемы. Анализ последних исследований и публикаций. Спортивный дайвинг - группа дисциплин подводного спорта.
Инициатором введения спортивного дайвинга как дисциплины подводного спорта считается Испанская подводная фредерация (FEDAS). 
В 2005 г. на Генеральной Ассамблее CMAS (Всемирная конфедерация подводной деятельности, созданная Жаком Ивом Кусто в 1959 г.) испанцы представили участникам дистанцию 300 м «комбинированное плавание» и заговорили о необходимости внесения спортивного дайвинга в список дисциплин подводного спорта. В 2008 г. CMAS включил спортивный дайвинг в подводный спорт, офрициально признав 5 дистанций. Это три индивидуальные дистанции: 300 м комбинированное плавание, ночной дайвинг, подъем 6-килограммового груза и две командные: 100 м полоса препятствий (парное упражнение) и брифинг (участвует команда из четырех человек). По статистике, с каждым годом увеличивается количество людей, занимающихся как рекреационным, спортивным и техническим дайвингом (приблизительное количество спортивных дайверов в США составляет около 4 млн в год [35] (подобная статистика в Украине к сожалению отсутствует), так и профессиональными водолазными и кессонными работами. В то же время, согласно данным Всемирной организации здравоохранения, во всем мире насчитывается около 285 млн человек, страдающих патологией органа зрения, при этом основными причинами нарушения зрения являются нескорректированные аномалии рефракции - близорукость, дальнозоркость или астигматизм - $43 \%$, катаракта - $33 \%$, глаукома - $2 \%$ [47]. Однако на сегодня определение медицинских противопоказаний к занятиям спортивным дайвингом, в частности у людей с патологией органа зрения, остается окончательно нерешенной проблемой.

Адаптация организма в условиях подводной среды, связанных с дисбарией, фиизическими нагрузками, гипотермией, психоэмоциональным стрессом и пр., обеспечивается координацией и интеграцией специализированных функций систем организма в пространстве и во времени [1, $3,48]$. Характер механизмов регуляции и фрункциональные резервы адаптации определяют устойчивость организма к нагрузкам, которые возникают в процессе погружения человека под воду. Известно, что важную роль в организации этого процесса играют сенсомоторные системы [3]. Сегодня не вызывает сомнения наличие прямой связи между острыми и хроническими поражениями различных структур зрительного анализатора у лиц, находившихся под повышенным давлением водной среды, с воздействием неблагоприятных фракторов гипербарии $[11,13$, $38,41]$. Однако в литературе имеется недостаточно данных о влиянии гипербарической среды на функционирование органа зрения как в норме, так и при патологии, также отсутствуют сведения о роли этого фактора в фоормировании общей патологии и о последующем развитии функциональных и органических офтальмологических изменений. Существующие исследования в основном представлены описанием единичных клинических случаев, многие из них противоречивы, работы, соответствующие критериям доказательной медицины касательно данной проблемы, практически отсутствуют $[6,8,26,36]$. В то же время формирование газовых пузырьков при повышенном давлении в передней камере глаза змеи было описано еще R. Boyle в 1607 г. [15].

Вышеизложенное делает проблему определения показаний и противопоказаний к занятиям как рекреационным, спортивным, техническим дайвингом, так и водолазными и кессонными работами, разработке стандартов офтальмологического скрининга, мониторинга и обследования дайверов, водолазных и кессонных рабочих, выбора специального оборудования, прогнозирования развития, просрилактику и лечение возможных развившихся офртальмологических осложнений у лиц с исходной (или прогнозируемой) развившейся патологией органа зрения крайне актуальной.

Цель исследования - обобщить данные литературы о физиологии и патологии зрительного анализатора в подводной среде, в частности при занятиях спортивным дайвингом.

Методы исследования: теоретический анализ и обобщение, систематизация, анализ научной и научно-методической литературы.

Результаты исследования и их обсуждение. Проведен анализ литературы с использованием электронных наукометрических баз данных Scopus, Web of Science, Ulrich's Periodicals, eLIBRARY.RU, Google Scholar, PubMed, Medline, украинских и российских баз данных (http:// www.yandex.ru, http://www.rambler.ru, http:// www.aport.ru, http://www.meta.ua, http://www. nbuv.gov.ua ), печатных научных статей, монографий и руководств, посвященных спортивному дайвингу, подводной и гипербарической медицине и патологии органа зрения за период с 1950 по 2015 гг.

\section{Влияние подводной среды на функцию} зрительного анализатора. В водной среде значительно изменяется фрункционирование зрительного анализатора, что вызвано как снижением освещенности и ухудшением видимости в воде, так и характеристиками преломляющих сил воды и сред глаза [29, 34, 43]. При отсутствии искусственного освещения видимость 
предметов, находящихся под водой, зависит от прозрачности воды и условий естественного освещения, что в свою очередь зависит от глубины расположения предмета в воде и времени суток. Количество отраженного от поверхности воды света зависит в основном от угла их падения на воду - чем больше угол падения, тем больше отражение. В дневное время, когда в средних широтах угол падения солнечных лучей невелик (менее $30^{\circ}$ ), поверхность воды отражает всего 2 \% лучей. В утреннее и вечернее время, когда угол падения приближается к $60^{\circ}$, количество отраженных лучей возрастает до $21 \%$. При волнении моря количество отраженных лучей становится во много раз больше. Вода активно поглощает световые лучи, при этом интенсивность дневного света на глубине 4,5 м составляет $1 / 4$, а на глубине 15 м - 1/8 от исходного. Опыт, полученный при погружениях на различные глубины в батискафрах, свидетельствует о том, что солнечный свет проникает лишь на глубину 450 м. Вода представляет собой синий светофильтр, тем более густой, чем толще слой воды. Все краски с увеличением глубины меняются. Так, красный цвет на глубине около 5 м становится бордовым, затем с увеличением глубины постепенно превращается в коричневый, а за пределами 12 м - в темно-зеленый. На глубине 20-30 м все цвета сизо-серые, однотонные и тусклые [3]. Дайверу (водолазу) необходимо знать, что, поранившись на глубине, он не увидит красной крови и может не заметить начавшегося кровотечения, учитывая то, что болевые ощущения в морской воде заметно притуплены, вследствие чего возможна незаметная большая потеря крови. Под водой человеку часто приходится пользоваться искусственным светом. При этом наиболее эфрфективными являются желтые лучи - своеобразный компромисс между красным светом, в основном поглощаемым водой, и голубым, интенсивно отражающимся от взвешенных в воде частиц. При работе в мутной воде может оказаться неэффрективным и искусственный свет, однако в случае необходимости можно воспользоваться приспособлением, которое представляет собой коническую трубку, напоминающую по фрорме мегафон, длиной 45-60 см, оба конца которой закрыты обыкновенным стеклом. Эта трубка, заполненная чистой водой, дает возможность видеть в мутной воде при прикладывании более узкого ее конца к глазу, а более широкого к рассматриваемому предмету. Заполнение таких трубок воздухом привело бы к возрастанию плавучести прибора и потребовало бы увеличить его прочность. Это простое приспособление было предложено Glass и известно среди водолазов под названием «глаза Гласса».

Преломляющие среды глаза (роговица, жидкость передней камеры глаза, различные слои хрусталика и стекловидное тело) имеют разные коэфрфициенты рефракции [16]. Общая преломляющая сила отдельных сред и всего глаза представляет собой сумму положительных и отрицательных показателей силы преломления отдельных составляющих элементов. При аккомодации в состоянии покоя преломляющая сила глаза составляет 62 диоптрии, из которых - 43 относятся к роговице и 19 - к хрусталику. Путем аккомодации преломляющая сила хрусталика может быть увеличена примерно на 10 диоптрий в возрасте 20 лет и на 4,5 диоптрии - в возрасте около 40 лет. Такая преломляющая сила глаза при аккомодации в покое наблюдается при проникновении световых лучей из воздушной среды, имеющей преломление 1,0, в преломляющие среды глаза, имеющие коэффрициент преломления от 1,336 до 1,406. В воде преломляющая сила существенно уменьшается, поскольку коэфрфициент преломления воды (1,33299 при $20^{\circ} \mathrm{C}$ и 760 мм рт.ст.) приближается к показателю преломления роговицы $(1,376)$ [3, 30]. Преломляющая сила значительно утрачивается и при непосредственном соприкосновении с водой глаз становится гиперметропическим в такой степени, что аккомодационные усилия не могут ее компенсировать [33]. Вследствие этого все видимые в водной среде предметы проецируются на сетчатке в кругах светорассеяния, а острота зрения резко ухудшается (в 100-200 раз). Если глаз с нормальной остротой зрения способен воспринимать раздельно две точки при минимальном угловом расстоянии между ними, равном 1', то в воде остаются невидимыми все объекты, толщина которых меньше 3-5 мм. Интересно, что лица с близорукостью, это когда изображение формируется не на сетчатке, а перед ней, видят в водной среде несколько лучше лиц с хорошим зрением. В данном случае жидкость со своими преломляющими способностями, как бы корректирует миопию, позволяет изображению фокусироваться не перед, а на самой сетчатке. При уменьшении освещенности, а также плохой контрастности между фоном и объектом острота зрения падает еще больше. При непосредственном соприкосновении глаза с водой уменьшается также поле зрения. Это происходит вследствие уменьшения преломления световых лучей, попадающих в глаз из водной среды, при этом на краевых зонах сетчатки не получается изображения тех точек внешнего пространства, которые 
проецируются на них в воздушной среде. При наличии между водой и глазом воздушной прослойки преломляющая сила глаза полностью сохраняется, поскольку световые лучи проникают через стекла в глаз не из водной, а из воздушной среды. В то же время наличие воздушной прослойки между водой и преломляющими средами глаза нарушает привычные представления о местоположении и величине предметов, находящихся в воде. Нарушение пространственного зрения связано с тем, что световые лучи, переходя из водной среды в воздушную, претерпевают преломление, в результате чего предметы в воде воспринимаются увеличенными и приближенными примерно на 1/4, а при наблюдении сверху кажутся приподнятыми. Расстояния между различными объектами воспринимаются неизмененными. Расположение и величина предметов под водой после некоторой тренировки оцениваются более верно, чем при первых погружениях, что обусловлено образованием новых условнорефлекторных связей. Показано, что гипербария также способствует умеренному снижению внутриглазного давления, независящему от температурных условий [58].

Особенности использования подводной оптики при патологии органа зрения. Как уже было указано, хорошая видимость под водой обеспечивается за счет маски. Стекла маски должны быть плоскими, так как искривленная поверхность вызывает рассеяние преломленного света и способствует зрительному восприятию предметов, находящихся под водой, в искаженном виде. При использовании большинства моделей масок поле зрения в результате рефракции и наличия у них оправы значительно уменьшается. В 1961 г. Barnard модифицировал глазной периметр для использования под водой и нанес на него зрительные поля, характерные для человека при надевании специальных очков и плавательных масок во время пребывания на воздухе и под водой. При сравнении полученных результатов с нормальными полями зрения было обнаружено, что сокращение последних при пребывании человека в маске/очках под водой выражено весьма значительно. Когда дайвер находится под водой в горизонтальном положении, особое значение приобретают верхние участки зрительных полей, уменьшение которых, по сравнению с нормой, выражено не столь значительно. Нижняя половина зрительного поля в данном случае менее важна. Нужно отметить, что при конструировании масок и очков следует обращать внимание на необходимость улучшения бокового зрения. В этом отношении могут оказаться полезными лицевые маски с широким обзором при условии преодоления искажений в восприятии наблюдаемых объектов, возникающих в результате изогнутой поверхности у стекол таких масок.

Для людей с патологией зрения современные маски оснащены системой диоптрических линз. Диоптрические линзы для маски имеют диапазон значений от -1 до -10 с шагом 0,5 и плюсовые диоптрические линзы от +1 до +6 с шагом 0,5 для диоптрий от +1 до +5 . При подборе маски с диоптрическими линзами необходимо учитывать коэффицциент преломления воды и выбирать линзы на 0,5 диоптрий меньше, чем исходное зрение [11]. Маски с диоптрическими линзами выпускаются разными производителями, среди них наиболее распространенными являются Look (TECHNISUB) (диапозон линз от -1 до -10 диоптрий.), Oceanic Ion (диапазон линз от -1 до -8 диоптрий), TUSA Splendive IV M-40 (диапозон линз от $+4,5$ до $-4,5$ диоптрий), TUSA M-24 Powerview (диапозон линз от $-1,5$ до -8 диоптрий), AQUA LUNG Look 2 (диапозон линз от -1 до -6 диоптрий), X-Vision, MARES (диапозон линз от +3 до -4 диоптрий), MANTIS , RIFFE (диапозон линз от -2 до -5 диоптрий) и др. [22], в то же время выбор маски для лиц с комбинированной и комплексной патологией органа зрения остается окончательно нерешенной задачей.

Контактные линзы и дайвинг. Согласно современным рекомендациям, лицам, занимающимся дайвингом, необходимо использовать только мягкие контактные линзы [7, 9, 14, 22]. Жесткие (полиметилметакрилатные) контактные линзы связаны с формированием пузырьков азота в прекорнеальной слезной пленке во время декомпрессии [42, 60], поэтому жесткие линзы обязательно должны иметь перфорации для выхода пузырьков газа из под линз (в противном случае не исключена возможность баротравмы роговицы) [55], при использовании жестких контактных линз описаны множественные случаи отека и баротравмы роговицы $[22,56]$. Наиболее частым осложнением при использовании мягких контактных линз в дайвинге является потеря линзы, что может повлечь за собой провалы за пределы рекреационных глубин или неконтролируемое всплытие [11].

Офтальмологические операции и дайвинг. На сегодня окончательно не определены возможности и противопоказания к занятию дайвингом, водолазными и кессонными работами после перенесенных офртальмологических операций [5, $19,23]$. К фракторам, повышающим риск послеоперационных осложнений после хирургических 
вмешательств на глазу, относят инфекционные осложнения (в т.ч. эндофртальмит), вызванные морскими организмами, загрязненной водой, наличием газа в передней камере или в стекловидном теле, отрицательном давлении в воздушном пространстве маски [11].

До начала 1990-х годов наиболее распространенной операцией для коррекции близорукости была радиальная кератотомия (РК), предложенная С. Федоровым. Однако РК связана с рядом побочных эффректов, в т.ч. возникновение ареолы, бликов, эфрфектом «вспышки», изменением остроты зрения, прогрессирующей дальнозоркостью, повышением риска разрыва роговицы и др., при перепадах давления этот метод дает существенное искажение остроты зрения [11]. Продолжается дискуссия о возможности разрыва роговицы в участках надрезов, сделанных в ходе выполнения РК, вследствие баротравмы [50]. В то же время отмечено, что хотя абсолютное давление увеличивается, перепад давлений в роговице крайне мал. Исключение могут составлять лишь единичные случаи чрезмерно сильного обжима маски. Ряд авторов не отмечают увеличения частоты офтальмологических осложнений у дайверов, которым была выполнена РК [49]. Согласно современным рекомендациям, рекреационные дайверы, которым была выполнена РК, должны выдержать трехмесячный реабилитационный период до первого погружения с последующим постоянным контролем обжима маски, в то же время пациентам, у которых близорукость была корректирована с использованием этой методики согласно программам ВМФ США невозможно заниматься подводным спортом/ работами, DAN также не рекомендует занятия дайвингом после РК [22]. С 1995 г. для коррекции дальнозоркости и астигматизма используется операция фооторефрактивной кератэктомии (ФРК) (с 1996 г. была разрешена ВМС США для дайверов) [22]. В отличие от РК, метод ФРК не требует выполнения надрезов на роговице, которые усиливают риск ее травматизации. ФРК имеет меньшее количество осложнений и более предсказуемый и устойчивый результат, чем РК, хотя у некоторых пациентов могут развиться инфрекционные осложнения или помутнение роговицы, что может ослабить остроту зрения. После этой операции погружения можно осуществлять через две недели при нормальном течении реабилитационного периода со $100 \%$ возвратом зрения, отсутствием болевого синдрома, фотофобии и др. На сегодня наиболее перспективной технологией коррекции патологии зрения (дальнозоркости, близорукости) является LASIK
(Laser Assisted In-Situ Keratomileusis). Эта методика приводит к более быстрому и лучшему восстановлению зрения, чем ФРК. Преимуществом данной операции является то, что она позволяет корректировать сильную близорукость с максимальным эфффектом и минимальным повреждением роговицы. Осложнения операции LASIK наиболее часто связаны с механическим повреждением и воспалением иссеченной роговицы, сухостью тканей глаза. Выделяют три варианта послеоперационных осложнений, которые возникают вследствие действия гипербарической среды после перенесенных офртальмологических операций: полный разрыв роговицы из-за обжима маски, кератит и смещение тканей рассеченной роговицы. В то же время подобные осложнения у дайверов не зафиксированы после использования LASIK. После LASIK необходимо как минимум на месяц воздержаться от погружений, а также делать продолжительные перерывы между сериями погружений в первое время после операции. Четкий офтальмологический мониторинг необходимо проводить в течение 5 лет после операции [21].

Фитнес-дайвинг и офтальмологическая патология. С учетом современных международных рекомендаций и консенсусов выделяют следующие противопоказания к занятиям дайвингом при патологии органа зрения [20, 21, 40, 44, 60]: наличие газа в глазу в раннем послеоперационном периоде, установленный полый орбитальный имплант, любое острое нарушение зрения (боль в глазах, диплопия, снижение остроты зрения и пр.), состояние после офтальмологических операций в период реконвалесценции, проблемы со зрением после перенесенной декомпрессионной болезни (ДКБ) или артериальной газовой эмболии (АГЭ), глаукома (при тяжелой потере зрения). В последнее время появились работы о влиянии гипербарии на функционирование органа зрения у людей с ангиоидными полосами сетчатки (синдром Гренблад-Страндберга). Показано, что погружения могут приводить к субретинальным геморрагиям, дальнейшему травматическому разрыву мембраны Bruch, повышению риска развития макулопатии, вследствие чего большинство офртальмологов считают наличие данной патологии является противопоказанием к занятиям дайвингом [4].

Острая патология зрительного анализтора и дайвинг. Наиболее частыми причинами возникновения острой патологии органа зрения у дайверов являются ДКБ, АГЭ, гипероксическая близорукость (при использовании гипероксических газовых смесей), кислородное отравление 
c поражением центральной нервной системы, баротравма глаза, укусы морских организмов, использование химических реагентов против запотевания маски, применение окситметазолина для ликвидации проблем с ушами, трансдермального скопаламина для ликвидации вестибулярных нарушений [11]. Так же описаны случаи центральной серозной хориоретинопатии [24], хориодальной ишемии [25], тяжелого кератита после дайвинга на красном коралловом рифе, требующего длительного лечения топическими стероидами, который связывают с воздействием нематоцист красных кораллов или токсин-продуцирующих органелл [28], нейропатии зрительного нерва вследствие баротравмы сфеноидального синуса [18]. Некоторые авторы отмечают, что частота изменений сетчатки у спортивных дайверов наблюдается в 43,3-56,2 \% случаев [64]. У дайверов, которые не ныряют очень часто и неглубоко существенной макулярной патологии (в том числе диагностированной при фрлуоресцентной ангиографии) не выявлено [19]. Ряд авторов отмечают, что макулярная патология в большинстве случаев определяется у лиц с ДКБ в анамнезе [51], что связывают как с васкулярной обструкцией хориодальной оболочки и сетчатки непосредственно внутрисосудистыми пузырьками азота, так и активации ими системы комплимента и коагуляции; важную роль отводят влиянию сорормированных свободных кислородных радикалов.

Баротраßма глаза. Наиболее часто причиной баротравмы глаза является обжатие маски или наличие пузырьков газа в передней камере глаза или стекловидном теле после витреоретинальной хирургии [10, 54]. Клиническими проявлениями баротравмы глаза являются отек век, экхимозы, субконъюнктивальные геморрагии, в более тяжелых случаях - диплопия, гифема [32, 53], также описаны такие симптомы, как орбитальное и орбитальное субпериостеальное кровотечение [62, 63], что в тяжелых случаях может приводить к компрессии зрительного нерва, повышению внутриглазного давления вплоть до потери зрения.

Гипероксическая близорукость. У людей, которые испытывают длительные воздействия гипероксических газовых смесей, могут возникнуть явления прогрессирующей близорукости, которая обратима, если воздействие гипероксических смесей прекращается. Хотя эта патология является наиболее распространенной у пациентов, перенесших повторные сеансы гипербарической экспозиции кислорода по медицинским показаниям, также подобная патология отмечена у дайверов, которые делали серии длительных погружений с газовой смесью с парциальным давлением кислорода 1.3 АТА [11].

Декомпрессионная болезнь. В структуре всех профрессиональных заболеваний людей, находившихся в условиях повышенного давления газовой и водной среды, доля ДКБ составляет более $80 \%$. Самостоятельно отмеченные симптомы ДКБ - 1,55 на 1000 погружений, леченной ДКБ - 5,72 на 100000 погружений [52]. Проблеме ДКБ в офртальмологии как в клинике, так и в эксперименте посвящено незначительное количество работ [31, 39, 45, 57]. «Глазной» манифестацией ДКБ (7-12 \% всех случаев ДКБ) являются нистагм, диплопия, дефекты поля зрения, скотомы, гомонимная гемианопия, орбикулярные глазные боли, кортикальная слепота, недостаточность конвергенции, окклюзия центральной артерии сетчатки, нейропатия зрительного нерва $[17,37,59]$. Невысокая частота газовой эмболии сосудов глаза с наибольшей вероятностью объясняется обильной васкуляризацией органа зрения. Экспериментально при введении воздуха в сонную артерию кролика удается вызвать появление пузырьков воздуха в артериях сетчатки, артерии резко сужаются, сосок зрительного нерва бледнеет. На глазном дне выделяется блестящая, серебристая сеть капилляров, содержащих воздух. В течение 1-2 мин воздух перемещается в вены и далее быстро исчезает. Таким образом, аэроэмболия сосудов глаза имеет кратковременный, преходящий характер. Предполагается, что при десатурации хрусталика может наступить нарушение в обмене веществ в связи с появлением в хрусталике свободного газа. Клиническими офртальмологическими проявлениями другой дисбарической патологии - АГЭ, отличающейся патогенетически, преимущественно связанной с пульмонарной баротравмой на подъеме, являются гемианопиаз или кортикальная слепота. На сегодня с целью диагностики патологии глазного дна при АГЭ и ДКБ (выявления пузырьков газа в сосудах сетчатки) рекомендуют использовать ретинальную ангиграфрию (в эксперименте пузырьки газа в ретинальных сосудах у овец при 6 ATA 30 мин. донного времени при быстрой декомпрессии были выявлены в 25,8 \% случаев), данное исследование является безопасным, неинвазивным и также позволяет оценить состояние церебральной циркуляции [46]. Лечением офтальмологических форм ДКБ или АГЭ являются рекомпрессия, гипербарическая оксигенотерапия.

Офтальмологические лекарственные препараты и дайвинг. Наиболее часто амбулаторно 
используемыми лекарственными препаратами в офртальмологии являются средства для лечения глаукомы, антибиотики и противовоспалительные агенты [2]. При наличии острого воспалительного процесса в глазу (когда применяются топические антибиотики, противовирусные препараты, стероиды) погружения противопоказаны [11, 15, 22]. Ингибиторы карбоангидразы (ацетазоламид, метазоламид) могут вызывать явления переферической парестезии, клинически похожей на неврологическую фрорму ДКБ (погружения возможны только через 4-6 нед. после начала терапии при отсутствии соответствующей симптоматики). При наличии депрессии, психических расстройств препарат должен быть отменен, дайвинг возможен только после восстановления всех соответствующих фрункций. Если пациент использует данные препараты, перед погружением необходим контроль общего анализа крови и электролитов сыворотки крови. Тимолол и другие местные бета-адреноблокаторы с осторожностью должны использоваться в холодной воде, в случаях нормального сердечного ритма погружения не противопоказаны, при наличии исходной брадиаритмии перед планированием погружений должна проводится консультация специалиста. Использование дипивефрина не является противопоказаноем к занятием дайвингом. Пациенты, начавшие лечение пилокарпином, должны быть четко обследованы на предмет наличия головной боли, что может симулировать проявления ДКБ после погружения [11].

Гипербарическая оксигенотерапия при патологии органа зрения. Гипербарическая оксигенотерапия (ГБО) как лечебная методика во многом обязана подводной медицине. На сегодня большинстве стран подводная и гипербарическая медицина являются частями единого целого. История широкого клинического использования ГБО насчитывает несколько более сорока лет. K 80-м годам XX ст. национальными обществами по баротерапии США, Франции, Италии, Японии, Китая и СССР были разработаны обширные списки показаний к ГБО. Чрезмерно широкое использование ГБО и новые научные открытия о патогенном влиянии свободнорадикальных фрорм кислорода потребовали пересмотра показаний к ГБО. На определенный период времени было приостановлено широкое использование ГБО, когда наиболее вероятно было получение патогенных эффректов лечебной гипероксии в связи с истощением структурного и нарушением регуляторного звеньев антиоксидантной защиты организма. В течение последних лет в развитых странах возобновился интерес к ГБО. Появился целый ряд публикаций, в которых представлен анализ экспериментальных и клинических исследований эфффективности ГБО различного уровня доказательности: от мнения отдельных экспертов до мета-анализа контролируемых клинических исследований. На сегодня показаниями к ГБО при патологии органа зрения являются ДКБ и АГЭ с поражением глаза, окклюзия центральной артерии сетчатки, окулярная и периокулярная газовая гангрена, цереброрино-орбитальный мукормикоз, периорбитальный некротизирующий фрасциит, отравление монооксидом углерода с патологией органа зрения, лучевая оптическая нейропатия, лучевой или митомицин-С индуцированный склеральный некроз, осложнения периорбитальной реконструктивной хирургии [2, 12]. Дискутабельными показаниями к ГБО остаются ишемическая оптическая нейропатия, ишемическая центральная венозная ретинальная окклюзия, окклюзия ветвей центральной ретинальной артерии с снижением зрения, кистозный макулярный отек, связанный с ретинальной венозной окклюзией, воспалительные (в т.ч. послеоперационные) послеоперационные процессы, ретинопатия Purtscher, лучевая ретинопатия, ишемия переднего сегмента, отслойка сетчатки при серповидноклеточной анемии, рефрактерный актиномикотический лакримальный каналиккулит, гангренозная пиодермия орбиты, рефрактерный синегнойный кератит.

\section{Выводы:}

1. Сегодня отсутствует окончательное мнения относительно глубины, частоты и длительности погружений, при которых возникают или обостряются изменения в функционировании органа зрения у человека.

2. Общей характерной особенностью воздействия повышенного давления на организм является временный, преходящий, обратимый характер происходящих изменений в фрункционировании ряда фризиологических систем организма. К осложнениям и специфическим заболеваниям, в частности, к развитию и прогрессированию патологии органа зрения, приводят нарушения правил и режимов спусков под воду, а также недооценка морфофрункционального состояния дайвера (водолаза, кессонного рабочего) перед погружением.

3. Травмы и заболевания органа зрения наиболее часто возникают при многократном воздействии на организм экстремальных фракторов подводного погружения, нарушении режимов декомпрессии и техники безопасных спусков. До настоящего времени нет четких доказательств возникновения отсроченных офртальмологических 
изменений, повреждений различных структур зрительного анализатора при занятиях рекреационным или техническим дайвингом, водолазными работами.

4. Проблема фитнес-дайвинга при офтальмологической патологии является совершенствование и создание специальной оптики для дайверов

\section{Литература}

1. Зальцман Г. Л. Основы гипербарической физиологии / Г. Л. Зальцман, Г. А. Кучук, А. Г. Гургенидзе. - Л.: Медицина, 1979. - 320 с.

2. Офртальмология : нац. рук. / под ред. С. Э. Аветисова, Е. А. Егорова, Л. К. Мошетовой и др. - М.: ГЭОТАРМедиа, 2008. - 944 с.

3. Смолин В. В. Водолазные спуски и их медицинское обеспечение / В. В. Смолин, Г. М. Соколов, Б. Н. Павлов. - М.: Слово, 2001. - 695 с.

4. Angulo Bocco M. Diving-related visual loss in the setting of angioid streaks : report of two cases / M. Angulo Bocco, L. Spielberg, G. Coppens et al. // Retin Cases Brief Rep. - 2012. - Vol. 6, N3. - P. 223-227.

5. Bennett M. H. Ocular tear film bubble counts after recreational compressed air diving / M. Bennett, D. Doolette, N. Heffernan // Undersea Hyperb Med. - 2001. - Vol. 28, N 1. - P. 1-7.

6. Bennett M. H. Randomized controlled trials in diving and hyperbaric medicine/ M. H. Bennett / Undersea Hyperb Med. - 2013. - Vol. 40, N 5. - P. 419-438.

7. Bennett Q. M. New thoughts on the correction of presbyopia for divers / Q. M. Bennett // Diving Hyperb Med. 2008. - Vol. 38, N 2. - P. 163-164.

8. Bove A. Diving medicine /A. Bove // Am J Respir Crit Care Med. - 2014. - Vol. 189, N 12. - P. 1479-1486.

9. Brown M. Cornea-contact lens interaction in the aquatic environment / M. Brown, I. Siegel // CLAO J. - 1997. Vol. 23, N 4. - P. 237-242.

10. Butler $F$. Orbital hemorrhage following face-mask barotraumas / F. Butler, N. Gurney // Undersea Hyperb Med. - 2001. - Vol. 28, N 1. - P. 31-34.

11. Butler F. Diving and hyperbaric ophthalmology / F. Butler // Surv Ophthalmol. - 1995. - Vol. 39, N 5. P. 347-366.

12. Butler F. K. Jr. Hyperbaric oxygen therapy and the eye / F. K. Jr Butler, C Hagan, H Murphy-Lavoie / / Undersea Hyperb Med. - 2008. - Vol. 35, N 5. - P. 333-387.

13. Cooke J. Intraocular pressure and retinal responses of dogs at 45,000 and 80,000 feet / J. Cooke / /Aerosp Med. 1970. - Vol. 41, N 3. - P. 283-289.

14. Cotter J. Soft contact lens testing on fresh water scuba divers /J. Cotter // Contact Intraocul Lens Med J. 1981. - Vol. 7, N 4. - P. 323-326.

15. Edmonds C. Diving medicine for scuba divers / Carl Edmonds, Bart McKenzie, John Pennefather, BobThomas. 2013 5th ed.

16. Gislén $A$. On the optical theory of underwater vision in humans /A. Gislén, L. Gislén // J Opt Soc Am A Opt Image Sci Vis. - 2004. - Vol. 21, N 11. - P. 2061-2064.

17. Guo B. Effect of rapid decompression on rat multifocal electroretinogram / B. Guo, X. J. Liu, Q. H. Fan, et al. // Zhonghua Lao Dong Wei Sheng Zhi Ye Bing Za Zhi. 2010. - Vol. 28, N 9. - P. 671-675. с патологией органа зрения, а также разработка методов прогнозирования и диагностики, лечения и профрилактики острых и хронических повреждений глаза. Это комплексная проблема современной офтальмологии, спортивной и профессиональной медицины и пока она далека от окончательного решения.

\section{References}

1. Zalzman G. L. Fundamentals of hyperbaric physiology / G. L. Zalzman, G. A. Kuchuk, A. G. Gurgenidze. - Leningrad: Meditsina, 1979.- 320 p.

2. Ophthalmology: National guidelines / ed. by S. E. Avetisov, E. A. Yegorov, L. K. Moshetova et al. - Moscow: GEOTAR-Media, 2008. - 944 p.

3. Smolin V.V. Diving slopes and medical care / V. V. Smolin, G. M. Sokolov, B. N. Pavlov. - Moscow: Mir, 2001.- 695 p.

4. Angulo Bocco M. Diving-related visual loss in the setting of angioid streaks : report of two cases / M. Angulo Bocco, L. Spielberg, G. Coppens et al. / Retin Cases Brief Rep. - 2012. - Vol. 6, N3. - P. 223-227.

5. Bennett M. H. Ocular tear film bubble counts after recreational compressed air diving / M. Bennett, D. Doolette, N. Heffernan // Undersea Hyperb Med. - 2001. - Vol. 28, N 1. - P. 1-7.

6. Bennett M. H. Randomized controlled trials in diving and hyperbaric medicine/ M. H. Bennett //Undersea Hyperb Med. - 2013. - Vol. 40, N 5. - P. 419-438.

7. Bennett Q. M. New thoughts on the correction of presbyopia for divers / Q. M. Bennett // Diving Hyperb Med. 2008. - Vol. 38, N 2. - P. 163-164.

8. Bove A. Diving medicine /A. Bove / / Am J Respir Crit Care Med. - 2014. - Vol. 189, N 12. - P. 1479-1486.

9. Brown M. Cornea-contact lens interaction in the aquatic environment / M. Brown, I. Siegel // CLAO J. - 1997. Vol. 23, N 4. - P. 237-242.

10. Butler $F$. Orbital hemorrhage following face-mask barotraumas / F. Butler, N. Gurney // Undersea Hyperb Med. - 2001. - Vol. 28, N 1. - P. 31-34.

11. Butler F. Diving and hyperbaric ophthalmology / F. Butler // Surv Ophthalmol. - 1995. - Vol. 39, N 5. P. $347-366$.

12. Butler F. K. Jr. Hyperbaric oxygen therapy and the eye / F. K. Jr Butler, C Hagan, H Murphy-Lavoie / / Undersea Hyperb Med. - 2008. - Vol. 35, N 5. - P. 333-387.

13. Cooke J. Intraocular pressure and retinal responses of dogs at 45,000 and 80,000 feet / J. Cooke / / Aerosp Med. 1970. - Vol. 41, N 3. - P. 283-289.

14. Cotter J. Soft contact lens testing on fresh water scuba divers /J. Cotter // Contact Intraocul Lens Med J. 1981. - Vol. 7, N 4. - P. 323-326.

15. Edmonds C. Diving medicine for scuba divers / Carl Edmonds, Bart McKenzie, John Pennefather, BobThomas. 2013 5th ed.

16. Gislén $A$. On the optical theory of underwater vision in humans /A. Gislén, L. Gislén // J Opt Soc Am A Opt Image Sci Vis. - 2004. -Vol. 21, N 11. - P. 2061-2064.

17. Guo B. Effect of rapid decompression on rat multifocal electroretinogram / B. Guo, X. J. Liu, Q. H. Fan, et al. // Zhonghua Lao Dong Wei Sheng Zhi Ye Bing Za Zhi. 2010. - Vol. 28, N 9. - P. 671-675. 
18. Hexdall E. Transient vision loss at depth to presumed barotraumatic optic neuropathy / E. Hexdall, F. Butler // Undersea Hyperb Med. - 2012. - Vol. 39, N 5. - P. 911-914.

19. Holden R. Ocular fundus lesions in sports divers using safe diving practices / R. Holden, C. D. Morsman, C. M. Lane // Br J Sports Med. - 1992. - Vol. 26, N 2. - P. 90-92.

20. Режим доступа: www. hse. gov. uk/diving/index. htm. - Health and Safety Executive. - Дата обращения 13.03.2015 (for information on the regulatory framework for diving at work, diver training and medical fitness).

21. Режим доступа: https://www. uhms. org/education/credentialing/diving-medicalexaminers. html.

22. Режим доступа: https://www. diversalertnetwork. org/1231. - Divers Alert Network. - Дата обращения 13.03.2015.

23. Huang E. T. Refractive change in response to acute hyperbaric stress in refractive surgery patients / E. T. Huang, M. D. Twa, D. J. Schanzlin, et al. / / J Cataract Refract Surg. 2002. - Vol. 28, N 9. - P. 1575-1580.

24. Ide W. W. Central serous chorioretinopathy following hypobaric chamber exposure/ W. W. Ide // Aviat Space Environ Med. - 2014. - Vol. 85, N 10. - P. 1053-1055.

25. Iordanidou V. Choroidal ischemia secondary to a diving injury / V. lordanidou, G. Gendron, C. Khammari et al. // Retin Cases Brief Rep. - 2010. - Vol. 4, N 3. - P. 262-265.

26. James P. B. Ocular fundus lesions in divers / P. B. James // Lancet. -1989. - Vol. 1, N 8640. - P. 731732.

27. Kania B. Comparative investigations of changes in the ocular fundus of divers / B. Kania, J. Krzyzak // Am J Respir Crit Care Med. - 2014. - Vol. 189, N 12. - P. 1479-1486.

28. Keamy J. Red coral ceratitis / J. Keamy, J. Umlas, Y. Lee // Cornea. - 2000. - Vol. 19, N 6. - P. 859-860.

29. Kelley J. S. Visual function in divers at 15 to 26 atmospheres pressure / J. S. Kelley, P. G. Burch, M. E. Bradley// Mil Med. - 1968. - Vol. 133, N 10. - P. 827-829.

30. Kent P. R. Vision underwater / P. R. Kent // Am J Optom Arch Am Acad Optom. - 1966. - Vol. 43, N 9. P. 553-565.

31. Kitte/ V. Observations on the eye of animals with caisson disease / V. Kittel, W. Schubert // Albrecht Von Graefes Arch Ophthalmol. - 1953. -Vol. 154, N 5. - P. 553-560.

32. Latham E. Diplopia due to mask barotraumas / E. Latham, K. van Hoesen, I. Grover //J Emerg Med. 2011. - Vol. 41, N 5. - P. 486-488.

33. Lieppman Michael E. Accommodative and convergence insufficiency after decompression sickness / Michael E. Lieppman //Arch Ophthalmol. -1981. - Vol. 99, N 3. P. 453-456.

34. Luria S. M. Underwater vision /SM Luria, JA Kinney // Science. - 1970. - Vol. 167, N 3924. - P. 1454-1461.

35. Lynch J. H. Diving medicine: a review of current evidence/ J. H. Lynch, A. A. Bove // J Am Board Fam Med. 2009. - Vol. 22, N 4. - P. 399-407.

36. Macarez R. Long-term effects of iterative diving on visual field, color vision and contrast sensitivity in professional divers / R. Macarez, Y. Dordain, M. Hugon et al. / / J Fr Ophtalmol. - 2005. - Vol. 28, N 8. - P. 825-831.

37. Mahon R. T. Decompression and decompression sickness / R. T. Mahon, D. P. Regis / / Compr Physiol. - 2014. Vol. 4, N 3. - P. 1157-1175.

38. Mehrpour M. Effect of scuba-diving on optic nerve and sheath diameters / M. Mehrpour, N. S. Shams-Hosseini, S. Rezaali // Med J Islam Repub Iran. - 2014. - Vol. 28. P. 89.
18. Hexdall E. Transient vision loss at depth to presumed barotraumatic optic neuropathy / E. Hexdall, F. Butler // Undersea Hyperb Med. - 2012. - Vol. 39, N 5. - P. 911-914.

19. Holden $R$. Ocular fundus lesions in sports divers using safe diving practices / R. Holden, C. D. Morsman, C. M. Lane // Br J Sports Med. - 1992. - Vol. 26, N 2. - P. 90-92.

20. Access mode: www. hse. gov. uk/diving/index. htm. - Health and Safety Executive. - Applied 13.03.2015 (for information on the regulatory framework for diving at work, diver training and medical fitness).

21. Access mode: https://www. uhms. org/education/ credentialing/diving-medicalexaminers. html.

22. Access mode: https://www. diversalertnetwork. org/1231. - Divers Alert Network. - Applied 13.03.2015.

23. Huang E. T. Refractive change in response to acute hyperbaric stress in refractive surgery patients / E. T. Huang, M. D. Twa, D. J. Schanzlin et al. / / Cataract Refract Surg. 2002. - Vol. 28, N 9. - P. 1575-1580.

24. Ide W. W. Central serous chorioretinopathy following hypobaric chamber exposure / W. W. Ide / / Aviat Space Environ Med. - 2014. - Vol. 85, N 10. - P. 1053-1055.

25. Iordanidou V. Choroidal ischemia secondary to a diving injury / V. lordanidou, G. Gendron, C. Khammari, et al. / / Retin Cases Brief Rep. - 2010. - Vol. 4, N 3. - P. 262-265.

26. James $P . B$. Ocular fundus lesions in divers / P. B. James // Lancet. -1989. - Vol. 1, N 8640. - P. 731732.

27. Kania B. Comparative investigations of changes in the ocular fundus of divers / B. Kania, J. Krzyzak // Am J Respir Crit Care Med. - 2014. - Vol. 189, N 12. -P. 14791486.

28. Keamy J. Red coral ceratitis / J. Keamy, J. Umlas, Y. Lee / / Cornea. - 2000. - Vol. 19, N 6. - P. 859-860.

29. Kelley J. S. Visual function in divers at 15 to 26 atmospheres pressure/ J. S. Kelley, P. G. Burch, M. E. Bradley // Mil Med. - 1968. - Vol. 133, N 10. - P. 827-829.

30. Kent P. R. Vision underwater / P. R. Kent // Am J Optom Arch Am Acad Optom. - 1966. - Vol. 43, N 9. P. 553-565.

31. Kitte/ V. Observations on the eye of animals with caisson disease / V. Kittel, W. Schubert / / Albrecht Von Graefes Arch Ophthalmol. -1953. -Vol. 154, N5. - P. 553-560.

32. Latham E. Diplopia due to mask barotraumas / E. Latham, K. van Hoesen, I. Grover //J Emerg Med. 2011. - Vol. 41, N 5. - P. 486-488.

33. Lieppman Michael E. Accommodative and convergence insufficiency after decompression sickness / Michael E. Lieppman //Arch Ophthalmol. - 1981. - Vol. 99, N 3. P. 453-456.

34. Luria S. M. Underwater vision /SM Luria, JA Kinney // Science. - 1970. - Vol. 167, N 3924. - P. 1454-1461.

35. Lynch J. H. Diving medicine: a review of current evidence / J. H. Lynch, A. A. Bove // J Am Board Fam Med. 2009. - Vol. 22, N 4. - P. 399-407.

36. Macarez R. Long-term effects of iterative diving on visual field, color vision and contrast sensitivity in professional divers / R. Macarez, Y. Dordain, M. Hugon, et al. // J Fr Ophtalmol. - 2005. - Vol. 28, N 8. - P. 825-831.

37. Mahon RT. Decompression and decompression sickness / R. T. Mahon, D. P. Regis / / Compr Physiol. - 2014. Vol. 4, N 3. - P. 1157-1175.

38. Mehrpour M. Effect of scuba-diving on optic nerve and sheath diameters / M. Mehrpour, N. S. Shams-Hosseini, S. Rezaali // Med J Islam Repub Iran. - 2014. - Vol. 28. P. 89. 
39. Mekjavic P. J. Decompression-induced ocular tear film bubbles reflect the process of denitrogenation / P. J. Mekjavic, I. B. Mekjavic // Invest Ophthalmol Vis Sci. - 2007. Vol. 48, N 8. - P. 3756-3760.

40. Modell M. M. Diving and hyperbaric medicine: an undergraduate's experience / M. M. Modell// Diving Hyperb Med. - 2014. - Vol. 44, N 3. - P. 174-175.

41. Molino $A$. Ophthalmological problems in underwater medicine / A. Molino // Ann Ottalmol Clin Ocul. - 1963. Vol. 89. - P. 778-790.

42. Mosse $P$. Underwater contact lenses / P Mosse // Br J Physiol Opt. - 1964. - Vol. 21. - P. 250-255.

43. Muntz W. R. Visual resolution under water/ W. R. Muntz, A. D. Baddeley, J. N. Lythgoe // Aerosp Med. - 1974. - Vol. 45, N 1. - P. 61-66.

44. Режим доступа: http://www. ndc. noaa. gov/ pdfs/NOAA_Medical_Standards_Procedures_Manual. pdf. NOAA Diving Medical Standards and Procedures. Manual. 2010. - Дата обращения: 13.03.2015.

45. Ostachowicz M. Z. History of the ophthalmological investigations in decompression sickness / M. Z. Ostachowicz // Bull Inst Marit Trop Med Gdynia. - 1987. - Vol. 38, N 3-4. - P. 207-209.

46. Parsons J. T. Retinal angiography: noninvasive, realtime bubble assessment from the ocular fundus / J. T. Parsons, C. R. Smith, J. Zhu, B. D. Spiess // Undersea Hyperb Med. - 2009. - Vol. 36, N 3. - P. 169-181.

47. Pascolini D. Global estimates of visual impairment: 2010 / D. Pascolini, S. P. Mariotti // Br J Ophthalmol. 2012. - Vol. 96, N 5. - P. 614-618.

48. Pennefather J. Physiology and Medicine of Diving/ J. Pennefather, W. Robyn. - Arnolds Publ. ed. by Alf Brubakk and Tom Neuman; 5th ed. - 2008.

49. Peters N. T. Effect of increased atmospheric pressure on radial keratotomy/ N. T. Peters, R. C. Jr. Borer, M. B. Strauss / / C Cataract Refract Surg. - 1999. - Vol. 25, N 12. - P. 1620-1623.

50. Peyraud-Gilly V. M. Macular functions in professional divers / V. M. Peyraud-Gilly, P. Daubas, T. Joly et al. / / J Fr Ophtalmol. - 2000. - Vol. 23, N 5. - P. 472-474.

51. Polkinghorne P. J. Ocular fundus lesions in divers / P. J. Polkinghorne, K. Sehmi, M. R. Cross et al. // Lancet. 1988. - Vol. 2, N 8625. - P. 1381-1383.

52. Ranapurwala S. I. Scuba diving injuries among Divers Alert Network members 2010-2011/ S. I. Ranapurwala, N. Bird, P. Vaithiyanathan et al. // Diving Hyperb Med. 2014. - Vol. 44, N 2. - P. 79-85.

53. Rudge F. W. Ocular barotrauma caused by mask squeeze during a scuba dive / F. W. Rudge // South Med J. - 1994. - Vol. 87, N 7. - P. 749-750.

54. Senn P. Ocular barostress and barotrauma. A study of 15 scuba divers / P. Senn, U. Helfenstein, M. L. Senn, et al. // Klin Monbl Augenheilkd. - 2001. - Vol. 218, N 4. P. 232-236.

55. Simon D. R. Adverse effects of contact lens wear during decompression / D. R. Simon, M. E. Bradley // JAMA. 1980. - Vol. 244, N 11. - P. 1213-1214.

56. Simon D. R. Corneal edema in divers wearing hard contact lenses / D. R. Simon, M. E. Bradley//Am J Ophthalmol. - 1978. - Vol. 85, N 4. -P. 462-464.

57. Tervo T. Permeability changes in cerebral, iridic, and retinal vessels during experimental decompression sickness in the rat / T. Tervo, J. Lehtosalo, V. P. Lehto, et al. // Aviat Space Environ Med. - 1980. - Vol. 51, N 2. - P. 137141.
39. Mekjavic $P$. J. Decompression-induced ocular tear film bubbles reflect the process of denitrogenation / P. J. Mekjavic, I. B. Mekjavic / / Invest Ophthalmol Vis Sci. - 2007. Vol. 48, N 8. - P. 3756-3760.

40. Modell M. M. Diving and hyperbaric medicine: an undergraduate's experience / M. M. Modell// Diving Hyperb Med. - 2014. - Vol. 44, N 3. - P. 174-175.

41. Molino $A$. Ophthalmological problems in underwater medicine / A. Molino // Ann Ottalmol Clin Ocul. - 1963. Vol. 89. - P. 778-790.

42. Mosse P. Underwater contact lenses / P Mosse // Br J Physiol Opt. - 1964. - Vol. 21. - P. 250-255.

43. Muntz W. R. Visual resolution under water/ W. R. Muntz, A. D. Baddeley, J. N. Lythgoe // Aerosp Med. - 1974. - Vol. 45, N 1. - P. 61-66.

44. Access mode: http://www. ndc. noaa. gov/ pdfs/ NOAA_Medical_Standards_Procedures_Manual. pdf. - NOAA Diving $\bar{M}$ Medical $\bar{S}$ tandards and Procedures. Manual. - 2010. Applied: 13.03.2015.

45. Ostachowicz M. Z. History of the ophthalmological investigations in decompression sickness / M. Z. Ostachowicz // Bull Inst Marit Trop Med Gdynia. - 1987. - Vol. 38, N 3-4. - P. 207-209.

46. Parsons J. T. Retinal angiography: noninvasive, realtime bubble assessment from the ocular fundus / J. T. Parsons, C. R. Smith, J. Zhu, B. D. Spiess // Undersea Hyperb Med. - 2009. - Vol. 36, N 3. - P. 169-181.

47. Pascolini D. Global estimates of visual impairment: 2010 / D. Pascolini, S. P. Mariotti // Br J Ophthalmol. 2012. - Vol. 96, N 5. - P. 614-618.

48. Pennefather J. Physiology and Medicine of Diving / J. Pennefather, W. Robyn. - Arnolds Publ. ed. by Alf Brubakk and Tom Neuman; 5th ed. -2008.

49. Peters N. T. Effect of increased atmospheric pressure on radial keratotomy/ N. T. Peters, R. C. Jr. Borer, M. B. Strauss / / Cataract Refract Surg. - 1999. - Vol. 25, N 12. - P. 1620-1623.

50. Peyraud-Gilly V. M. Macular functions in professional divers / V. M. Peyraud-Gilly, P. Daubas, T. Joly et al. / / J Fr Ophtalmol. - 2000. - Vol. 23, N 5. - P. 472-474.

51. Polkinghorne P. J. Ocular fundus lesions in divers / P. J. Polkinghorne, K. Sehmi, M. R. Cross et al. // Lancet. 1988. - Vol. 2, N 8625. -P. 1381-1383.

52. Ranapurwala S. I. Scuba diving injuries among Divers Alert Network members 2010-2011/ S. I. Ranapurwala, N. Bird, P. Vaithiyanathan et al. // Diving Hyperb Med. 2014. - Vol. 44, N 2. - P. 79-85.

53. Rudge F. W. Ocular barotrauma caused by mask squeeze during a scuba dive / F. W. Rudge // South Med J. - 1994. - Vol. 87, N 7. - P. 749-750.

54. Senn P. Ocular barostress and barotrauma. A study of 15 scuba divers / P. Senn, U. Helfenstein, M. L. Senn et al. // Klin Monbl Augenheilkd. - 2001. - Vol. 218, N 4. P. 232-236.

55. Simon D. R. Adverse effects of contact lens wear during decompression / D. R. Simon, M. E. Bradley // JAMA. 1980. - Vol. 244, N 11. - P. 1213-1214.

56. Simon D. R. Corneal edema in divers wearing hard contact lenses / D. R. Simon, M. E. Bradley//Am J Ophthalmol. - 1978. - Vol. 85, N 4. - P. 462-464.

57. Tervo T. Permeability changes in cerebral, iridic, and retinal vessels during experimental decompression sickness in the rat / T. Tervo, J. Lehtosalo, V. P. Lehto et al. // Aviat Space Environ Med. - 1980. - Vol. 51, N 2. - P. 137141. 
58. Van de Viere $S$. Influences of atmospheric pressure and temperature on intraocular pressure/ S. Van de Viere, P. Germonpre, C. Renier //Invest Ophthalmol Vis Sci. 2008. - Vol. 49, N 12. - P. 5392-5396.

59. Vozza R. Ophthalmological aspects of the decompression syndrome, with special reference to explosivedecompression / R. Vozza // Minerva Med. - 1958. - Vol. 49, N 63-64. - P. 3131-3135.

60. Weiss $M$. Standards on medical fitness examinations for Navy divers / M. Weiss // Int Marit Health. - 2003. Vol. 54, N 1-4. - P. 135-143.

61. Williamson J. A. Diving and the soft content lens/ J. A. Williamson / / Med J Aust. - 1984. - Vol. 140, N 13. P. 801.

62. Woo D. Non-traumatic subperiosteal orbital hemorrhage secondary to barotrauma/ D. Woo, S. Rogers, J. Leong et al. // Orbit. 2012. - Vol. 31, N5. - P. 347-349.

63. Yeoh R. Barotraumatic ocular haemorrhage sustained while scuba diving / R. Yeoh, M. Singh // Clin Experiment Ophthalmol. - 2008. - Vol. 36, N 6. - P. 581-582.

64. Zhou D. Observation and management of retinal changes related to diving in professional divers/ D. Zhou, W. Wei, B. Tian et al. // Chin Med J (Engl). - 2014. Vol. 127, N 4. - P. 729-733.

kryuch_ye@ukr.net

instructor@divecentre.com.ua

alex@divecentre.com.ua
58. Van de Viere S. Influences of atmospheric pressure and temperature on intraocular pressure/ S. Van de Viere, P. Germonpre, C. Renier //Invest Ophthalmol Vis Sci. 2008. - Vol. 49, N 12. - P. 5392-5396.

59. Vozza R. Ophthalmological aspects of the decompression syndrome, with special reference to explosivedecompression / R. Vozza // Minerva Med. - 1958. - Vol. 49, N 63-64. - P. 3131-3135.

60. Weiss $M$. Standards on medical fitness examinations for Navy divers / M. Weiss // Int Marit Health. - 2003. Vol. 54, N 1-4. - P. 135-143.

61. Williamson J. A. Diving and the soft content lens / J. A. Williamson / / Med J Aust. - 1984. - Vol. 140, N 13. P. 801.

62. Woo D. Non-traumatic subperiosteal orbital hemorrhage secondary to barotrauma/ D. Woo, S. Rogers, J. Leong et al. // Orbit. 2012. - Vol. 31, N5. - P. 347-349.

63. Yeoh R. Barotraumatic ocular haemorrhage sustained while scuba diving / R. Yeoh, M. Singh // Clin Experiment Ophthalmol. - 2008. - Vol. 36, N 6. - P. 581-582.

64. Zhou D. Observation and management of retinal changes related to diving in professional divers / D. Zhou, W. Wei, B. Tian et al. // Chin Med J (Engl). - 2014. Vol. 127, N 4. - P. 729-733.

Поступила 10.02. 2016 